\title{
Kajian Pustaka: Hubungan Durasi Kerja dengan Pneumokoniosis pada Pekerja Tambang Batubara
}

\author{
Aditya Henerik Risamasu ${ }^{1 *}$, Ifat Kabiran ${ }^{2}$, Intan Trikumala Damayanti ${ }^{3}$, \\ Thalia Febrianti ${ }^{4}$, Nurmalia Marina Adji N. ${ }^{5}$ \\ 1,2,3,4,5Program Pendidikan Dokter, Fakultas Kedokteran, Universitas Muhammadiyah Malang
}

\begin{abstract}
ABSTRAK
International Labor Organization menyatakan bahwa hampir 2.34 juta pekerja meninggal akibat pekerjaannya setiap tahun. Sekitar $86.23 \%$ diakibatkan penyakit yang berhubungan dengan pekerjaan. Pneumoconiosis merupakan salah satu penyakit yang dapat ditemukan dalam pertambangan batu bara. Pneumoconiosis terbagi menjadi beberapa tipe antara lain silicosis, asbestosis, mixed dust fibrosis, coal worker's pneumoconiosis (CWP) dan tipe yang lain (Zhang). CWP adalah penyakit kronis dan ireversibel yang menjadi masalah kesehatan public. Batubara dengan kapasitas pembakaran yang lebih besar memiliki risiko terbesar menyebabkan CWP. Penelitian ini dilakukan untuk mengkaji pustaka tentang durasi kerja dengan peningkatan kejadian CWP pada pekerja tambang batu bara. Dua puluh sumber referensi diambil dari PubMed, ScienceDirect, ResearchGate, dan Google Scholar. Artikel yang direview dalam laporan ini dalam rentang tahun 2000 hingga 2020. Sebagian besar penelitian menyatakan bahwa terjadi peningkatan prevalensi kasus CWP. Kasus CWP meningkat seiring dengan jumlah paparan debu yang banyak dan durasi kerja yang lama. Secara subyektif bahwa paparan debu, usia, dan masa kerja tidak memiliki hubungan yang signifikan dengan gangguan pernafasan, dan lebih menekankan pada hubungan penggunaan APD dan kebiasaan merokok. Efek lain yang ditimbulkan berupa PPOK, kematian, dan beban biaya Kesehatan. Kesimpulan pada penelitian ini menyatakan bahwa durasi kerja yang lebih lama meningkatkan kejadian CWP pada pekerja tambang batu bara.
\end{abstract}

Kata kunci: penyakit akibat kerja; batubara; pneumoconiosis

\begin{abstract}
Introduction: The International Labor Organization estimates that nearly 2.34 million workers die as a result of their work each year. About $86.23 \%$ were caused by occupational diseases. Pneumoconiosis is a disease that can be found in coal mining. Pneumoconiosis is divided into several types, including silicosis, asbestosis, mixed dust fibrosis, coal worker's pneumoconiosis (CWP), and other types (Zhang). CWP is a chronic and irreversible disease that is a public health problem. Coal with a higher combustion capacity has the greatest risk of causing CWP. Purpose: This research was conducted to review the literature on the duration of work with an increase in the incidence of CWP in coal mine workers. Method: Twenty reference sources were drawn from PubMed, ScienceDirect, ResearchGate, and Google Scholar. The articles reviewed in this report range from 2000 to 2020. Results: Most studies suggest an increase in the prevalence of CWP cases. The incidence of CWP increases with the amount of dust exposure and the long duration of work. Discussion: Subjectively, dust exposure, age, and years of service did not have a significant relationship with respiratory problems, and put more emphasis on the relationship between PPE use and smoking habits. Other effects include COPD, death, and health costs. Conclusion: The conclusion of this study states that a longer work duration increases the incidence of CWP in coal mine workers.
\end{abstract}

Keywords: occupational illness; coal; pneumoconiosis

*Korespondensi penulis:

Nama : Aditya Henerik Risamasu

Instansi : Fakultas Kedokteran Universitas Muhammadiyah Malang

Alamat : Jl. Bendungan Sutami 188A Malang, Jawa Timur, Telp.: +62-341-552443/+62-341-582260

Email : risamasuaditya@gmail.com 


\section{Pendahuluan}

Pemberian makan merupakan bagian penting Penyakit akibat kerja terutama pada bidang pertambangan batubara masih menjadi penyumbang permasalahan dalam penyakit dan kematian di sektor industri. Beberapa penyakit yang dapat ditemukan pada pertambangan batubara antara lain: pneumokoniosis, kanker, penyakit paru obstruktif kronis (PPOK), emfisema, infeksi kulit, dan gangguan pendengaran. ${ }^{1}$ Inhalasi debu anorganik menimbulkan beberapa kejadian penyakit paru salah satunya adalah pneumokoniosis. Pneumokoniosis terbagi menjadi beberapa tipe antara lain silicosis, asbestosis, mixed dust fibrosis, coal worker's pneumoconiosis (CWP) dan tipe yang lain. ${ }^{2}$

Batubara adalah batuan sedimen yang mudah terbakar, berkarbon, dan sebagian besar terdiri dari karbon dan hidrokarbon. Varietas batubara diklasifikasikan menjadi empat jenis atau peringkat tingkat batubara, masing-masing dengan perbedaan energinya sebagai akibat dari peningkatan tekanan, panas, dan waktu. Batubara dengan kapasitas pembakaran yang lebih besar memiliki risiko terbesar menyebabkan pneumokoniosis penambang batubara (CWP), karena merupakan radikal bebas di permukaan. ${ }^{3,4}$

CWP adalah penyakit kronis dan ireversibel yang menjadi masalah kesehatan publik. $^{2}$ Prevalensi CWP yang tinggi diduga karena paparan pekerjaan di tambang bawah tanah tidak menguntungkan, karena perkiraan persentase debu batubara yang dapat terhidrup sebesar 40 sampai 95\%. Selain itu, rata-rata geometric silika bebas lebih tinggi dibandingkan dengan lingkungan kerja lain. ${ }^{5}$ Pada individu yang dicurigai mengidap pneumokoniosis biasanya muncul setelah paparan jangka waktu yang lama. Pneumokoniosis merupakan penyakit yang dapat dicegah, namun tidak dapat diobati. ${ }^{6}$

Telah lama diketahui bahwa paparan debu merupakan faktor utama bahaya pada pekerja tambang batubara. ${ }^{7}$ Akumulasi debu batubara pada jaringan paru dapat menimbulkan bermacam-macam temuan klinis seeperti antrakosis jalan nafas yang tidak berbahaya hingga fibrosis jaringan paru yang ireversibel serta emfisema. Pada gambaran radiologi foto polos paru dapat ditemukan nodul berukuran $<1$ $\mathrm{cm}$ pada zona atas, meskipun gambaran ini tidak khas (Perret). Gambaran klinis pneumokoniosis tidak khas dan sering disangka sebagai keluhan pada paru lain seperti bronkitis kronis, PPOK dan emfisema. Dahak berwarna kehitaman (melanoptysis) dapat muncul apabila nodul mengalami nekrosis dan mencair. ${ }^{6}$

Berdasarkan estimasi preliminar oleh International Labor Organization, hampir 2.34 juta pekerja meninggal akibat pekerjaannya setiap tahun. Sekitar $86.23 \%$ diakibatkan penyakit yang berhubungan dengan pekerjaan, dan angka ini terus meningkat. Kerugian ekonomi tahunan juga meningkat karena penyakit akibat kerja dan kecelakaan, berkisar antara USD 3.3 triliun. ${ }^{7}$ Oleh karena hal di atas, pada kajian pustaka ini membahas bagaimana hubungan durasi kerja terhadap penyakit akibat kerja yakni CWP pada pekerja tambang batubara.

\section{Metode}

Studi ini menggunakan beberapa kajian melalui beberapa jurnal nasional dan internasional yang diperoleh dari 20 sumber referensi melalui pencarian di PubMed, Science Direct, ResearchGate, dan Google Scholar dengan penerbitan dari tahun 2015 sampai dengan tahun 2020. Kriteria inklusi yang digunakan adalah: 1) Jurnal yang termasuk dalam penelitian ini datang dalam bentuk artikel penelitian, editorial, komentar, tinjauan literature dalam penelitian kuantitatif, kualitatif atau metode campuran; 2) Jurnal kesehatan atau terkait yang dipublikasikan pada rentang tahun 2015-2020; 3) Jurnal yang memuat topik tentang masalah kesehatan pada pekerja pertambangan 
batubara; 4) Jurnal nasional dan internasional bereputasi baik terindeks scopus maupun non scopus.

\section{Hasil dan Pembahasan}

Kepadatan insiden CWP diperkirakan memiliki tren yang cenderung meningkat dari tahun 2005 hingga 2024. Model APC memiliki kesesuaian yang baik dalam memprediksi secara akurat tren insiden CWP dan mencerminkan potensi risiko CWP di tambang batubara terbuka. Model ini dapat membandingkan risiko insiden bagi CWP dalam subkelompok usia, periode, dan kelompok. ${ }^{8}$ Pada literatur lain, sebuah studi oleh Blackley (2018) didapatkan bukti adanya peningkatan prevalensi CWP dengan meningkatnya tindakan transplantasi paru pada penderita CWP berat di Amerika Serikat. ${ }^{6}$

Hubungan antara kejadian CWP dengan durasi kerja dari kajian systematic review sejumlah 2945 artikel. Pada sembilan studi yang diteliti terdapat enam penelitian yang menunjukkan adanya efek batubara terhadap insiden penyakit paru intersisial. ${ }^{9}$ Dari 127 pekerja tambang batubara semua pekerja berjenis kelamin laki-laki dengan usia rata-rata 40,5 $\pm 8,9$ Tahun, 63 (49,6\%) terdiagnosis CWP. Lamanya paparan debu batubara berkisar antara 7 hingga 390 bulan dengan rata-rata selama 129,1 $\pm 82,2$ bulan. Dari 127 pekerja tambang batubara, 49,6\% di antaranya telah terkonfirmasi menderita CWP. Dalam penegakan diagnosis dan tindak lanjut CWP di Turki, pemeriksaan secara berkala menjadi komponen terpenting sebagai perlindungan sekunder dalam hal yang berhubungan dengan risiko pekerjaan. Pemeriksaan radiografi paru digunakan sebagai komponen diagnosis dini yang sangat diperlukan pada karyawan yang berisiko terkena CWP. Selain itu, pelaksanaan program skrining harus dievaluasi dengan penilaian risiko dan informasi paparan. ${ }^{10}$
Berdasarkan sebuah studi kohort risiko durasi terhadap paparan sangat signifikan. Hasil ini menunjukkan bahwa pengaturan waktu kerja mungkin merupakan langkah alternatif untuk pengendalian risiko. CWP adalah penyakit yang tidak dapat kembali, namun dapat dicegah di bawah kontrol debu yang efektif. pemantauan debu dan program perlindungan kesehatan yang dilaksanakan sejak akhir 1950 tahun terusmenerus tampaknya berkontribusi secara efektif terhadap pengendalian penyakit. Total populasi dari laporan ini adalah 173.646 dan 10.821 untuk pekerja batubara yang terpapar debu dan pasien dengan CWP. Prevalensi pooled CWP adalah $6,02 \%$. Prevalensi ini dianalisis sesuai dengan area geografis penelitian, selama penyelidikan bertahun-tahun, menganalisis durasi paparan debu, peringkat batubara, derajat CWP, jenis pekerjaan dan kategori penambangan batubara, dll. ${ }^{11}$

Faktor risiko yang berhubungan selain paparan debu batubara adalah kadar debu itu sendiri, masa kerja ( $\geq 10$ tahun), dan kebiasaan merokok. $^{12,13}$ Pada studi yang dilakukan oleh Varona et al, (2018) didapatkan data prevalensi pneumokoniosis sangat tinggi dan ditemukan berhubungan dengan paparan debu batubara, paparan kerja 25 tahun atau lebih dan bekerja di perusahaan menengah. ${ }^{14}$ Sedangkan pada studi lain didapatkan rerata paparan debu yang dibutuhkan hingga menimbulkan CWP pada pekerja tambang adalah 37,21 tahun. ${ }^{3}$

Terdapat tren penurunan durasi paparan terhadap pneumokoniosis dan silicosis, yang menunjukkan resiko debu menjadi lebih serius. ${ }^{11}$ Pada penelitian yang dilakukan oleh Qomariyatus Sholihah et al (2015) menunjukan bahwa terdapat hubungan yang bermakna antara sif kerja, masa kerja dan budaya keselamatan dan fungsi paru pada pekerja tambang batu bara, dimana sift kerja merupakan variabel yang paling berpengaruh. Pekerja tambang batu bara memiliki waktu sift siang (pagi, siang, sore) dan sif malam. 
Permasalahan lebih banyak terjadi pada pekerja sift malam karena irama faal tubuh manusia yang tidak dapat menyesuaikan kerja malam dan tidur. Kerja sif malam merupakan sistem yang berlawanan dengan irama sirkadian. Kelainan pola tidur sebagai salah satu bentuk gangguan irama sirkadian yang dialami pekerja sift memiliki konsekuensi patologis berupa peningkatan kadar sitokin proinflamasi dalam darah karena penurunan sistem kekebalan dan antioksidan dalam tubuh. ${ }^{15}$ Hal tersebut tidak sesuai dengan penelitian Fauziah et al (2020) yang menyatakan bahwa pajanan debu, usia, dan masa kerja tidak memiliki hubungan yang signifikan terhadap keluhan pernafasan pada pekerja tambang. ${ }^{8}$

Hubungan paparan debu kumulatif dapat memprediksi tingkat kejadian CWP. Tingkat kejadian CWP meningkat bertahap dengan meningkatnya paparan debu kumulatif. Pada studi kohort yang melibatkan 43.742 pekerja batu bara. 1847 pekerja dengan CWP dan di prediksi 4.300 kasus CWP baru. Sehingga penting untuk mengendalikan konsentrasi debu di tempat kerja untuk mengurangi timbulnya pneumokoniosis. ${ }^{16}$

Penentuan tingkat paparan debu batubara dan resiko pekerja batubara terjadi CWP berbeda di setiap bagian pekerja. Pada pekerja bagian belt-inspektor \#4 konsentrasi paparan debu $4.5 \mathrm{mg} / \mathrm{m}^{3}$, lebih tinggi dibandingkan pekerja dibagian inspektur pompa pipabatu bara $0.9 \mathrm{mg} / \mathrm{m}^{3}$ dan belt inspector \#2 \#3 $2.7 \mathrm{mg} / \mathrm{m}^{3}$. Dengan rata-rata kejadian terjadi pneumokoniosis yaitu pada tahun ke-5 selama terpapar debu batubara. ${ }^{17}$ Periode paparan debu debu rata-rata pada pasien dengan CWP adalah 26,7 tahun, periode laten rata-rata 29,3 tahun dan usia rata-rata didiagnosis adalah 50,3 tahun. ${ }^{4}$

Partikel debu di tempat kerja dapat memberikan efek ketidaknyamanan dalam bekerja. Adapun pajanan debu dalam waktu yang lama dapat memberikan pengaruh negatif terhadap kesehatan tenaga kerja. Melakukan sosialisasi mengenai bahaya dan dampak pajanan debu kepada pekerja. Selain itu, meningkatkan kesadaran karyawan akan pentingnya memakai APD (Alat Pelindung Diri) yang sesuai dengan jenis pekerjaannya, serta melakukan perpindahan atau rotasi karyawan jika sudah bekerja selama 1 tahun sehingga dapat mengurangi waktu pajanan. ${ }^{15}$

Faktor risiko lain yang berhubungan kejadian CWP pada studi kohort memperkirakan bahwa dari 19.116 pekerja terdapat 141 pekerja batubara yang mungkin menderita CWP pada 2012. Hal tersebut dikarenakan otoritas atau peraturan yang ditetapkan tidak layak dalam hal mengenai skrining dan diagnosis CWP. ${ }^{18}$ Sebagian besar pasien dengan pneumokoniosis, pada foto radiologis didapatkan kelainan diparenkim paru $(87,1 \%)$ dan pleura $(12,9 \%)$ berupa perseluungan halus bulat di zona kanan bawah hal ini berhubungan dengan posisi sudut percabangan bronkus utama kanan yang lebih curam dibandingkan bronkus utama kiri. ${ }^{19}$

Komplikasi yang ditimbulkan dari CWP adalah PPOK dan perburukan kondisi yang mengakibatkan kematian. Pada perokok berat dengan paparan debu batubara serta silika, penumokoniosis berat semua berhubungan dengan peningkatan resiko PPOK. ${ }^{12}$ Tingkat kematian akibat CWP adalah 19,19\%. Rerata masa hidup setelah terdiagnosis adalah 12,1 tahun. ${ }^{20}$ Pada studi yang dilakukan oleh Tomaskova et al (2017) yang dilakukan di Republik Ceko didapatkan rasio mortalitas standar (SMR) kematian pekerja dengan CWP lebih tinggi daripada populasi pria umum. ${ }^{22} \mathrm{CWP}$ selain menimbulkan masalah pada permasalahan angka kesakitan dan kematian, juga memiliki dampak terhadap bidang sosioekonomi.

Paparan debu di tempat kerja dapat menyebabkan berbagai penyakit paru-paru, termasuk pneumokoniosis dan juga penyakit paru obstruktif kronik (PPOK). Adanya kondisi COPD dan pneumokoniosis dapat memperparah kondisi 
pekerja. Perlunya optimalisasi pencegahan terhadap kejadian pneumokoniosis dan langkahlangkah penting untuk mengurangi paparan debu dan meningkatkan pengendalian penyakit di lingkungan industri. ${ }^{23,24,25,26}$ Peningkatan kejadian CWP menimbulkan pembengkakan biaya kesehatan. Di Cina, kerugian kesehatan akibat kasus baru CWP diperkirakan akan terus meningkat selama lima tahun ke depan. Otoritas yang tepat harus dibentuk untuk mengelola peningkatan dalam kerugian kesehatan akibat CWP. ${ }^{14,27,28,29}$

\section{Kesimpulan}

Durasi kerja yang lebih lama meningkatkan kejadian CWP pada pekerja tambang batu bara. Perlu dilakukan pencegahan untuk penyakit akibat kerja dengan memberikan edukasi mengenai CWP, merokok, dan penggunaan APD yang baik dan benar. Selain itu perlu dibuat sebuah kebijakan kesehatan seperti memantau kesehatan pekerja secara rutin, mengatur waktu kerja untuk mengurangi durasi paparan terhadap debu batubara, dan kebijakan lain yang sesuai dengan panduan penyelenggaraan $\mathrm{K} 3$.

\section{Ucapan Terima Kasih}

Penulis mengucapkan terima kasih kepada para pihak yang telah memberi dukungan khususnya Fakultas Kedokteran, Universitas Muhammadiyah Malang.

\section{Referensi}

1. Barber C, Fishwick D. Pneumoconiosis. Medicine. 2016;44(6):355-358.

2. Zhang $\mathrm{Y}$, Zhang $\mathrm{Y}$, Liu B, Meng X. Prediction of the length of service at the onset of coal workers' pneumoconiosis based on neural network. Archives of Environmental \& Occupational Health. 2019;2019:1-9.
3. Wang XT, Zhang G. [Dose-response relationship between different respirable coal dust exposures and pneumoconiosis risk]. Zhonghua Liu Xing Bing Xue Za Zhi. 2020;41(7):1068-1071.

4. Wang Y, Chen H, Long R, Yang M. Health economic loss measurement and risk assessment of new cases of coal worker's pneumoconiosis in China. Safety Science. 2020;122:1-1.

5. Beyan AC, Bahadir H, Çimrin A. Coal workers' pneumoconiosis and surveillance: A 5-year experience. Eurasian Journal Pulmonol 2020;22:118-22

6. Blackley DJ, Hall NB, Halidin CN, Laney AS. Current Review of Pneumoconiosis Among US Coal Miners. Curr Environ Health Rep. 2019;6(3):137-147.

7. Torres Rey $\mathrm{CH}$, Ibañez Pinilla M, Briceño Ayala L, Checa Guerrero DM, Morgan Torres G, Groot de Restrepo H, et al. Underground Coal Mining: Relationship between Coal Dust Levels and Pneumoconiosis, in Two Regions of Colombia, 2014. BioMed Research International. 2015;2015:1-8.

8. Fauziah A, Budiyono B, Raharjo M. Keluhan Subyektif Gangguan Pernafasan pada Pekerja di Area Stockpile Batubara Jambi. Jurnal Ilmiah Mahasiswa. 2020;10(3):61-69.

9. Hall NB, Blackley DJ, Halldin CN, Laney AS. Current Review of Pneumoconiosis Among US Coal Miners. Curr Environ Health Rep. 2019;6(3):137-147.

10. Han B, Liu H, Zhai G, Wang Q, Liang J, Zhang M, et al. Estimates and Predictions of Coal Workers' Pneumoconiosis Cases among Redeployed Coal Workers of the Fuxin Mining Industry Group in China: A Historical Cohort Study. PLoS ONE. 2016;11(2):e0148179. 


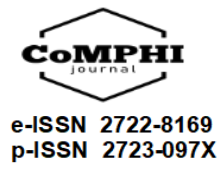

11. Han L, Gao Q, Yang J, Wu Q, Zhu B, Zhang $\mathrm{H}$, et al. Survival Analysis of Coal Workers' Pneumoconiosis (CWP) Patients in a StateOwned Mine in the East of China from 1963 to 2014. Int J Environ Res Public Health. 2017;14(5):489.

12. Md. Ismail CT. Occupational Hazards in Mining and Manufacturing Sector: An Analysis on Disease Claims in Malaysia. UUM Journal Of Legal Studies. 2014;5:5168.

13. Beer C, Kolstad HA, Søndergaard K, Bendstrup E, Heederik D, Olsen KE, et al. A systematic review of occupational exposure to coal dust and the risk of interstitial lung diseases. Eur Clin Respir J. 2017;4(1):1264711.

14. Varona M, Pinilla MI, Briceno L, Groot H, Narvaes D, Palma M, et al. Evaluation of the exposure to coal dust and prevalence of pneumoconiosis in underground mining in three Colombian departments. Biomedica. 2018;38(4):467-478.

15. Sholihah Q, Hanafi AS, Wanti W, Bachri AA, Hadi S. Analisis Sif Kerja, Masa Kerja Dan Budaya Keselamatan Dan Kesehatan Kerja Dengan Fngsi Paru Pekerja Tambang Batu Bara. Jurnal Kesehatan Masyarakat. 2015;10(1):24-28.

16. Perret JL, Plush B, Lachapelle P, Hinks TSC, Walter C, Clarke P, et al. Coal mine dust lung disease in the modern era. Respirology. 2017;22(4):662-670.

17. Zhang Q, Huang D, Li M. Study and Application on Risk Assessment Method of Coal Worker Pneumoconiosis Based on Logistic Regression Model. Study and

18. Application on Risk Assessment Method of Coal Worker Pneumoconiosis Based on Logistic Regression Model. Journal of Risk Analysis and Crisis Response. 2018;8(3):157-162.
19. Simanjuntak ML, Pinontoan OR, Pangemanan JM. Relationship Between Level of Dust, Work Period, Use of Mask and Smoking with Pneumoconiosis Occurrence on Cement Collector Workers at Cement Packing Unit PT. Tonasa Line Bitung. JIKMU. 2015;5(5):520-532.

20. Siswati S, Diyanah KC. Analisis Risiko Pajanan Debu (Total Suspended Particulate) Di Unit Packer PT. X. Jurnal Kesehatan Lingkungan. 2017;9(1):100-110.

21. Mo J, Wang L, Au W, Su M. Prevalence of coal workers' pneumoconiosis in China: a systematic analysis of 2001-2011 studies. Int J Hyg Environ Health. 2014;217(1):46.

22. Tomaskova H, Splichalova A, Slachtova H, Urban P, Hajdukova Z, Landecka I, et al. Mortality in Miners with CWP in the Czech Republic in the Period 1992-2013. Mar. International Journal of Environmental Research and Public Health. 2017;14(3):269.

23. Fan Y, Xu W, Wang Y, Wang Y, Yu S, Ye Q. Association of occupational dust exposure with combined chronic obstructive pulmonary disease and pneumoconiosis: a cross-sectional study in China. BMJ Open. 2020;10(9):e038874.

24. Li Y, Xian W, Xu H, Sun J, Han B, Liu H. Time trends and future prediction of coal worker's pneumoconiosis in opencast coal mine in China based on the APC model. BMC Public Health. 2018;18:1010.

25. Zhang C, Myers J. Pneumoconiosis. Atlas of Lung Pathology, Atlas of Anatomic Pathology. New York: Springer-Verlag New York; 2017.

26. Zhang $\mathrm{Y}$, Zhang $\mathrm{Y}$, Liu $\mathrm{B}$, Meng $\mathrm{X}$. Prediction of the length of service at the onset of coal workers' pneumoconiosis based on neural network. Archives of Environmental \& Occupational Health. 2019;2019:1-9. 
27. Zhao H, Xie Y, Wang J, Li X, Li J. Pulmonary rehabilitation for pneumoconiosis: protocol for a systematic review and meta-analysis. BMJ Open. 2019;9(8):e025891.

28. Ikhsan M. Proporsi dan Gambaran Radiologi Pneumokoniosis Pada Pekerja yang Terpajan Debu di Tempat Kerja. Jurnal Respirologi Indonesia. 2019;39(4):266-271.

29. Yong M, Anderle L, Lenaerts H, Derwall R, Brand D, Morfeld P. The Risk of Developing Coal Workers' Pneumoconiosis in a German Inception Cohort of Coal Miners of Ruhr Area - Results after 30 Years of Follow-up. Ann Lung Cancer. 2018;2(1):39-47 